\title{
The Values of Being Small and Nimble
}

\author{
Peter Christian Murphy
}

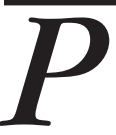

eter Christian (Chris) Murphy had worked his way up the "food chain" at ATET for 19 years, culminating in his position as Sales Center Vice President for South Florida. When be and a coworker realized there was an opportunity in the marketplace for a small, nimble company to take advantage of emerging communications technology that a stodgy, lumbering corporation would have trouble integrating into its service package, Chris decided to jump into an entrepreneurial opportunity.

\section{NEJE: What is your new venture called and what are} your roles in it?

Murphy: The company is called Global Linking Solutions, or GLS. We're a managed network and security provider and I'm the president and COO. We're a small company so I get to do a little bit of everything. An important part of my responsibilities is focusing on setting the strategic direction for GLS.That means developing and shaping a sound business plan and constantly adjusting to the ever-changing marketplace.

I also get to work in a number of tactical areas such as sales, financial operations, marketing, engineering, product development, systems development, process engineering, staffing, and even cleaning up after our Friday staff lunch.

My partner and I started this company from scratch in 1999 and now we have about 50 employees. All of our systems have been built internally and I am part of the team that guides the development of our tools and processes, which in a service business means you're going " $24 / 7$."

\section{NEJE: What was the path you took to get you where you are today?}

Murphy: I was working for AT\&T in South Florida when I met Michael Scanlon. Mike supported my team as the Data Technical Manager and he helped my group win some very significant accounts. Mike and I both felt there was a big need in the marketplace for someone who could do a good job of building networks for clients. Most of the integrators and solutions-providers looked at the wide area network as just an add-on to their regular business and they weren't very good at designing and implementing the wide area network. The carriers didn't understand customer solutions and were not very skilled in implementing networking and security equipment.

Mike and I decided to build a company that would design and build data networks and we were going to do it better than anyone else. We had had a high success rate within AT\&T, but we knew there were constraints on what we could offer and how fast we could deliver on client needs.

In 1999, Mike and I left AT\&T determined to build our own company and make it more nimble and responsive to client requirements.

\section{NEJE: What did you do for capital?}

Murphy: We developed a strong business plan and started to look for funding. Fortunately, we didn't have to look very far. Mike's dad, Jack Scanlon, already well known as a leader in the telecommunications industry, decided to fund our startup company and we were literally off to the races.

We started to implement our business plan in July 1999. One of our first moves was to hire away four other AT\&T executives so we could start attacking the marketplace aggressively. Lucky for us we didn't know what we could or couldn't do! We were confident we had identified an important market niche. GLS won some pretty big accounts right away.

\section{NEJE: Was it a case of beginner's luck?}

Murphy: No, we had put together the right mix of service products and people to make a go of it long term. Howwever, we realized after a year in business that the service mix we provided, especially if we sold a carrier-only deal, was becoming commoditized. That meant that GLS was not "sticky" enough. There was no reason for our clients to remain loyal to us. We knew we would have to do something different in the data networking market-something value added-so that we would become more important and differentiated from our competitors.

We decided to seek additional funding to build a Network Operations Center that would allow us to offer a suite of managed network and security services. In October 2000, we launched three new offerings: Managed Frame Relay, Managed Virtual Private Networks (VPN) and Managed Firewall.

Slowly, but surely, we started to gain new clients and hold on to our existing ones.

\section{NEJE: Who are your main competitors?}

Murphy: GLS is a small, managed wide area network provider; this means we have two different sets of competitors. First, we compete against the likes of AT\&T, Qwest, MCI, and the Bell operating companies in the Managed 
Frame Relay and VPN market segments. Those are the "big guns." In the VPN arena, there is another group of specialized and smaller companies that we compete against including Netifice, Clearpath, Virtella, Megapath, and Aubeta.

\section{NEJE: And then there's tiny GLS.}

Murphy: Exactly. For a small company to succeed, you must clearly distinguish yourself from everyone else. GLS differentiates itself against the high-end companies, like AT\&T, with managed offers that match up well on a featurefunctionality basis, but at a much more reasonable price. Since we are a much smaller company than an AT\&T, we can also be more flexible. Customers are very appreciative when solutions are custom tailored to their needs rather than taken "off the shelf." Our customers also like the fact that they are important to us and have easy access to everyone who works for GLS. That sure beats sitting on hold and getting the runaround at one of the big customer care bureaucracies.

In the VPN arena, we compete with a bunch of niche VPN providers. They have all invested in building their networks to deliver VPN capabilities at reasonable prices. We find we are usually very similar in pricing to these niche folks and sometimes their offerings even approach GLS on featurefunctionality.

\section{NEJE: So it's barder to make yourself seem different and better.}

Murphy: The difference between us and the other VPN players is we are also trying to manage a private network to deliver service. These small companies have to use their best resources looking internally at their own network infrastructures and not on their customers.

Additionally, when GLS builds a network, we use topquality research components from the leading DSL business customers, such as Covad, New Edge, and the Bell Companies. Since we use only the best (and most expensive) network components, the diversity, redundancy, and reliability with a GLS VPN network will always be far superior to those competitors of ours who cannot afford, or do not choose, to use these best-in-class components.

We don't own the network and none of the traffic is dependent on GLS infrastructure, so the client doesn't have to worry about our solvency as a company. If there were concerns or fears about our corporate solvency, that could put the client's entire network at risk. Literally, if we owned the network and stopped functioning, the customer's network could vanish. That's critical, because several of our closest competitors appear to be losing money with their business model while GLS has turned a profit each of the last three years.
NEJE: Even with these advantages, was there one day when you knew you bad broken through the competitive "clutter" and you were on your way?

Murphy: Yes! Our big break came in early 2001 when we sold a fully managed DSL VPN to Domino's Pizza. At that time, I don't think you could have found a DSL VPN, so we had an early position as the market leader. As one might expect, we learned lots of lessons with our Domino's client, and that's truly the case when you are pioneering a new market segment. DSL VPN has been a great boon for our company and we continue today to manage some very large retailers. We now have DSL providers working with us to deliver our managed VPN services over their own DSL circuits.

Our managed services business has grown, GLS became profitable in 2002 and continues to be profitable today. In October 2003, GLS self-funded a move to a new 15,000square-foot facility, which includes a diesel generator to protect against black- and brown-outs, an OC48 ring, and new furniture and computers for our NOC. We continue to add new tools and we have rolled out a whole new suite of managed servers and security products. It seems like we have come a long way, but I feel we are just getting started. In 2005 , we will begin offering our services to the federal government, having just been approved by the GSA.

NEJE: That's all very impressive. Are there certain people or events in your life that you can look back to and credit with belping you become so successful?

Murphy: I was about nine years old when I went to this cowboy camp with a friend of mine. We had a lot of fun riding horses and doing cowboy "stuff." Well, what I didn't know was this was a Christian cowboy camp and we were required to go to church every night. Anyway, I was away from home for the first time in my life and I guess I was a little lonely and homesick. They had a preacher there and he introduced me to this carpenter who has watched over me and guided me ever since. I may have ignored Him and His advice for periods of my life, but I strive to work for Him and for my family.

\section{NEJE: What was the biggest break you ever got before starting GLS?}

Murphy: I guess it was when AT\&T promoted me to run the South Florida operation. I got to live at the beach in Fort Lauderdale for seven years and gain some great work experience that prepared me for entering the entrepreneurial world.

NEJE: Would you say you also had great disappointments?

Murphy: I wish I had become an entrepreneur much earlier in life. Not only have I learned so much about business 
and life every day, but also, I would have earned millions if we had started GLS during the "dot com" boom.

\section{NEJE: What impact did your education bave on your success?}

Murphy: I was not academically inclined and actually took 18 months off from college to mature some before graduating from Ramapo College in New Jersey. I joined AT\&T right out of college as a sales representative and they put me through three months of training where they taught me about sales. As you might expect, I learned a whole lot of stuff that really wasn't all that important. I think that everything I have learned of any lasting importance, I learned on the job. You have to experiment with ideas that you think will work, you have to try and make them work and then rework them and try again.

When an idea works the way you want it to work, you have to make sure you are getting the most mileage out of that idea. If one of your ideas doesn't appear to be successful, and you have tried to rework it a few times, you need to quit trying to fix it and spend time on things that are working or begin to implement new ideas.

NEJE: Is there anything you would change in your life if you could go back in time?

Murphy: As a said earlier, I would have become my own boss much sooner. In fact, I should have been an entrepreneur right after college. While I learned a lot working for "Mr. Big," I think I could have learned a lot more and a lot faster enrolled in the "entrepreneurial school of hard knocks."

NEJE: How about some of the jobs you bad growing up and bow they shaped you as a person?

Murphy: My first job was actually an entrepreneurial position as a clam digger on Long Beach Island. I was 13 years old and I had a 14-foot aluminum boat that I would take out and clam for four or five hours, then sell the clams I dug up at the fish market for two cents apiece.

My life lesson from that job was to concentrate on the work at hand and not to let sharks scare you! I also had a job as a kid running the bumper cars at an amusement park, running an ice cream parlor, and I was even the head chef for a time at a gourmet restaurant. I learned how to lead a team, how important it is for everyone to feel empowered in a team, and how crucial it is to find an efficient process and then stick with it.

I also made a lot of friends at work and always tried to have fun even when there was pressure. Matter of fact, the more pressure on us, the more fun we had and it's the same way today.

\section{NEJE: What was your family upbringing like?}

Murphy: I was adopted as a baby by two loving parents. I was taught to be honest, help those less fortunate than me, and to work hard. I was also taught to have fun when I worked because work without fun is just a burden.

NEJE: Where do you see yourself going in the future? Murphy: When I was part of the corporate world, I always thought about when I would no longer have to work. I haven't really considered my long-range plans, but I will be open to going wherever the Lord leads me. Am I content with my job? Well, I have a great job now because I get to do a little of everything and I am always learning. I am continually challenged and I work with a great group of people. I use the word "content" because I think we should always be able to do things quicker and better. I will say that I do enjoy my work and I feel blessed.

\section{NEJE: What's in store for GLS?}

Murphy: I see GLS really growing into a significant company in the not-too-distant future. We are in a growing field, especially where network security is concerned. That growth curve should continue to expand significantly during the next decade. As long as we continue to provide innovative, managed solutions that solve real problems, and offer tremendous value, we will be the kind of company that sneaks up and surprises people. 